\title{
MAKNA PENGALAMAN PELATIH BERINTERAKSI DENGAN LUMBA- LUMBA DALAM PERTUNJUKAN "DOLPHIN SHOW" OCEAN DREAM SAMUDRA
}

\author{
Nahemia Audrian \\ E-mail: \\ Nahemiaudrian@hotmail.com
}

\begin{abstract}
Human - animal interaction has always been a phenomenon throughout hundreds of years. One of the cleverest animal species that have high inteligence capability in communication are dolphins. Dolphins are one of the cetacean group that often being shown in various places such as theme park, circus, entertainment, research and also medication centre. This involvement of dolphins usually attached with the role of trainers that always interact while training those dolphins. This research aimed to discover the meaning of trainers and dolphins' interaction experience in "Dolphin Show" Ocean Dream Samudra - Ancol. The meaning of life value in implicating communication aspects used by trainers becoming analysis foundation. This research was held in Ocean Dream Samudra - Taman Impian Jaya Ancol. This research uses Collaizi's (1978) model as data analysis techniques and the triangulation sources of data. Interaction between trainers and dolphins is based on the feeling of love for animals in which supported by incorporating communication aspects such as verbal, gesture, objects, ultrasonic whistle, focus in eye sight, and telepathy. The changes in meaning produced by symbol and the consistency, discipline and reward management in training also support the interaction process. Miss comunication that occur during shows, covered by the ability of acting improvisation. The connection between trainers and dolphins enabling communication between human and animals.
\end{abstract}

Keywords: interspecies communication, antrozoology, dolphin trainers, phenomenology

\begin{abstract}
Abstrak
Interaksi manusia dengan hewan telah menjadi fenomena yang selalu terjadi selama berabad-abad. Salah satu hewan yang memiliki kapabilitas kecerdasan tinggi dalam berkomunikasi ialah lumba-lumba. Lumba-Lumba ialah salah satu mamalia laut yang sering di pertunjukan di berbagai wahana wisata, sirkus, hiburan, juga penelitian maupun pengobatan. Keterlibatan lumba-lumba ini tidak terlepas dari peran pelatih yang selalu berinteraksi dalam melatih lumba-lumba. Penelitian ini bertujuan untuk mengetahui makna pengalaman pelatih dalam berinteraksi dengan lumba-lumba dalam pertunjukan "Dolphin Show" di Ocean Dream Samudra - Ancol. Pemaknaan nilai-nilai hidup dalam pengimplikasian jenis komunikasi yang diterapkan pelatih dalam metode pelatihan menjadi dasar pembahasan. Peneltian dilakukan di dolphinarium Ocean Dream Samudera - Taman Impian Jaya Ancol. Penelitian ini menggunakan pendekatan fenomenologi interpretatif dengan pendekatan model Collaizi (1978) sebagai teknik analisis data beserta triangulasi sumber data. Interaksi antar pelatih dan lumba-lumba didasarkan oleh rasa cinta pada hewan yang didukung oleh penggunaan jenis komunikasi seperti verbal, gestur, objek, peluit ultrasonik, fokus tatapan mata, dan bahasa telepati. Interaksi didukung juga oleh perubahan makna simbol, proses konsisten disiplin dan pemberian reward dalam proses latihan. Kesalahan berinteraksi yang terjadi saat pertunjukan ditutupi oleh kemahiran pelatih dalam improvisasi acting. Koneksi yang terjalin antar pelatih dan lumba-lumba memungkinkan komunikasi antar manusia dan hewan dapat terjadi.
\end{abstract}

Kata kunci: komunikasi antarspesies, antrozoologi, pelatih lumba-lumba, fenomenologi 


\section{Pendahuluan}

Fenomena interaksi manusia dengan hewan telah berlangsung sejak ribuan tahun yang lalu, sejak zaman manusia purba, manusia selalu hidup berdampingan dengan hewan. Seperti yang dikatakan oleh Robinson dalam bukunya yang berjudul The Waltham Book of Human-Animal Interaction, manusia telah menjinakkan serigala muda sejak 500 ribu tahun yang lalu, dan menjadikan hewan liar sebagai peliharaan telah dilakukan oleh kerajaan Mesir dan Yunani Kuno (Robinson, 1995).

Terbukti oleh survei yang dilakukan organisasi GFK (Growth from Knowledge, 2016) menjabarkan bahwa sebanyak lebih dari setengah, yakni 56 persen orang di dunia memiliki hewan peliharaan baik itu anjing, kucing, ikan, burung, reptil dan lain lain. Dapat disimpulkan bahwa setengah dari populasi dunia pernah berinteraksi dengan hewan peliharaan mereka, namun proses berinteraksi ini jarang diteliti pemaknaannya baik dari segi manusia maupun dari segi hewan itu sendiri.

Menurut Bimo Walgito (2003: 65) interaksi merupakan suatu hubungan antara individu satu dengan individu lainnya dimana individu yang satu dapat mempengaruhi individu yang lainnya sehingga terdapat hubungan yang saling timbal balik. Sedangkan, secara etimologi dalam bahasa Inggris, "hewan" disebut animal, dari bahasa Latin yaitu "animalis", yang berarti "memiliki napas" (Cresswell, 2010). Kata "hewan" biasanya digunakan untuk merujuk hanya kepada anggota nonmanusia dalam taksonomi kerajaan Animalia. Terkadang, hanya kerabat dekat manusia seperti mamalia dan vertebrata lainnya. (Merriam-Webster, 2017).

Berdasarkan observasi sehari-hari, komunikasi dengan hewan sangatlah sering peneliti lakukan, biasanya pada hewan peliharaan seperti anjing atau kucing. Hewan bisa berkomunikasi dengan manusia menggunakan suara, atau lewat perilaku mereka, berupa isyaratisyarat atau penggabungan gerakan (behaviour).

Menelaah pemaknaan dalam berinteraksi dengan hewan, pemilihan hewan yang sesuai dengan kapabilitas kognitif yang mendekati manusia sangat diperlukan. Lumba-Lumba ialah salah satu mamalia laut yang sering di pertunjukan di berbagai wahana wisata maupun sirkus karena kecerdasannya. Kecerdasan lumbalumba yang signifikan ini sering dipergunakan manusia dalam berbagai penelitian, hiburan maupun pengobatan. Sejalan dengan artikel sains.kompas.com yang mengatakan bahwa lumba-lumba dikenal sebagai mamalia laut cerdas. Ia punya kelebihan dalam komunikasi dengan sebangsanya serta mampu berinteraksi dengan manusia. Kecerdasan lumba-lumba bahkan mengalahkan beberapa mamalia lainnya. (Wiji, 2012)

Menurut Ranneft, Eaker \& Davis (2001) dalam Aquatic Mamals Journal, lumba-lumba masuk ke dalam kategori cetacea. Cetacea adalah sebutan bagi ordo mamalia perairan yang tersebar luas dan beragam yang terdiri dari paus, lumbalumba, dan ikan pesut.

Seperti yang diungkapkan oleh Thomas White (2007), Professor of Ethics di Loyola Marymount University di Los Angeles dalam buku yang berjudul Indefense of Dolphins "Lumba-lumba sebagai 'Orang nonmanusia' memenuhi syarat sebagai individu yang paham akan konsep moral". Dr. Lori Marino (dalam Martin, 2016), seorang ahli zoologi dari Emory University di Atlanta, Amerika Serikat, menerangkan bahwa di dalam otak lumba-lumba terdapat banyak fitur yang terkait dengan kecerdasan tinggi seperti lipatan korteks dan jumlah neuron yang sebanding dengan manusia.

Kecerdasan yang sangat signifikan tersebut membuat lumba-lumba menjadi salah satu binatang yang mudah untuk dilatih dan diajarkan. Kemampuan lumba-lumba yang terlatih sangatlah diminati banyak orang untuk ditonton sehingga banyak ditampilkan dalam wahana- 
wahana taman hiburan. Dalam melatih lumbalumba diperlukan pengalaman dalam melatih hewan lainnya terutama mamalia air. Selain itu, skill akting, akrobat, menari, public speaking, dan performance sangatlah diperlukan untuk menjadi pelatih penampil dalam pertunjukan lumbalumba (Kittleson, 2013).

Namun, proses pelatih tersebut dalam menempuh edukasi dan melatih hewan sehingga timbul interaksi sedemikian rupa merupakan sebuah bentuk fenomena yang jarang disadari orang awam. Kebanyakan dari manusia hanya dapat menikmati pertunjukan yang disuguhkan, namun tidak mampu memahami bagaimana proses sebuah pertunjukan itu dapat berjalan dengan baik sehingga dapat menjadi suatu karya seni yang beraspek komunikasi antarspesies.

Indonesia pada hakikatnya merupakan negara yang mempunyai potensi wisata yang tinggi karena memiliki keanekaragaman alam, baik flora maupun fauna yang tersebar di seluruh wilayah Indonesia. Tertulis juga dalam pasal 1 butir 7 UU No. 5 Tahun 1990 tentang Konservasi Sumber Daya Alam Hayati dan Ekosistemnya dijelaskan bahwa ikan dan ternak tidak termasuk satwa liar, tetapi termasuk dalam pengertian satwa. Jika dicermati, bisa diartikan bahwa lumba-lumba yang masih hidup di lautan bebas merupakan satwa liar, tetapi jika lumba-lumba tersebut telah masuk konservasi, dipelihara, diternakkan dan dimanfaatkan sesuai dengan ketentuan yang ada maka lumba-lumba tersebut merupakan satwa, bukan satwa liar dan juga termasuk binatang ternak (Undang - Undang Republik Indonesia, 1990).

Lumba-lumba yang telah diadopsi, dipelihara atau masuk balai konservasi yang di operasikan manusia biasanya dipelihara di tempat bernama Dolphinarium. Sfetcu mengatakan, Dolphinarium adalah akuarium untuk lumbalumba. Lumba-lumba biasanya disimpan di kolam besar, meskipun sesekali mereka disimpan dalam kandang di laut terbuka, baik untuk penelitian maupun untuk pertunjukan publik.

\section{Tinjauan Pustaka dan Kerangka Pemikiran}

Popularitas lumba-lumba yang melejit di tahun 1960-an, menjadikan bermunculnya banyak dolphinarium di seluruh dunia sehingga membuat lumba-lumba dapat diakses masyarakat. Di Amerika Serikat, yang paling dikenal adalah Sea World Marine-Mamalia Park, sedangkan di Indonesia salah satu terbesar yang dikenal ialah Ocean Dream Samudera - Ancol Jakarta. Dalam website resmi Ancol (www.ancol.com) Ocean Dream Samudra yang berlokasi di Ancol - Jakarta Utara ini merupakan perwujudan cita-cita gubernur Jakarta Ali Sadikin pada tahun 1974 tentang perlunya sarana rekreasi yang mengenalkan kepada masyarakat tentang laut beserta potensinya. Ocean Dream Samudra merupakan Edutainment Theme Park bernuansa konservasi alam yang memberikan pengalaman untuk mengenal lebih dekat dan menyayangi aneka satwa. Ocean Dream Samudra merupakan unit oceanarium terbesar yang terdiri dari pentas lumba-lumba, pentas singa laut, pentas aneka satwa, peragaan satwa, akuarium ikan laut dan tawar serta taman yang merupakan habitat beraneka macam burung. Disisi lain terdapat pula banyak protes dan gerakan-gerakan yang mengecam kegiatan pertunjukan sirkus lumba-lumba keliling yang sangat keji karena sistem pengangkutan, penampungan dan latihan yang sangat tidak memadai, Pemerintah hanya mengizinkan lumba-lumba digunakan dalam pentas hiburan bila kondisinya baik untuk binatang tersebut, tapi realitanya kerap tidak demikian karena sirkus, lumba-lumba dibawa keliling (Washarti, 2016). Hal ini sangatlah memilukan karena kebanyakan dari pelatih lumba-lumba sendiri ialah pecinta lumba-lumba. Terlebih dalam melatih lumba-lumba atau hewan apapun diperlukan kasih sayang dan passion agar 
proses interaksi dapat berjalan lancar, sehingga pemaknaan yang benar secara intrinsik dari seorang pelatih lumba-lumba perlu diteliti.

Pengalaman pelatih lumba-lumba dalam prosesnya berhubungan dan berinteraksi dengan lumba-lumba yang berhasil sangatlah menarik untuk diteliti. Kemampuan pelatih dalam mengimplikasikan konsep interaksi manusiahewan sangat menarik untuk diteliti maknanya. Berkaitan dengan hal ini maka studi fenomenologi cocok membahas penelitian ini karena studi fenomenologi merefleksikan pengalaman langsung manusia, sejauh pengalaman itu secara intensif berhubungan dengan suatu objek (Kuswarno, 2009: 1).

Menurut Vardiansyah (2008: 3) pengalaman ialah hasil persentuhan alam dengan panca indra manusia. Berasal dari kata peng-alam-an. Pengalaman memungkinkan seseorang menjadi tahu dan hasil tahu ini kemudian disebut pengetahuan. Mengalami, menjalani sekian peristiwa dalam hidup dengan sadar oleh seorang individu dapat disebut pengalaman. Pengalaman tidak jauh korelasinya dengan persepsi. Pengalaman akan membentuk persepsi seseorang akan suatu hal. Mulyana (2012: 194) menyatakan bahwa ketiadaan pengalaman terdahulu dalam menghadapi suatu objek jelas akan membuat seseorang menafsirkan objek secara semata atau pengalaman yang mirip. Maka pengalaman membentuk pola pikir dan pengetahuan seseorang seperti yang digagas oleh MarleauPonty (dalam Sobur, 2013: 18) bahwa "semua pengetahuan dunia, bahkan pengetahuan ilmiah saya, diperoleh dari beberapa pengalaman akan dunia.

Dalam studi fenomenologi, Hall dan Lindzey (dalam Sobur 2013: 13) mengatakan bahwa fenomenologi ialah penelitian yang mendeskripsikan data (secara harafiah disebut the givens, yang terberi) tentang pengalaman langsung sehingga esensial adanya pengalaman sadar untuk mengetahui dunia secara langsung ketika berhubungan dengannya (Sobur, 2013: 19)
Dapat disimpulkan bahwa pengalaman merupakan sebuah proses seorang individu mengalami alam di sepenelitirnya secara sadar dan melibatkan proses afektif, kognitif serta psikomotor didalamnya sejalan dengan yang disampaikan Husserl (dalam Sobur, 2013: 37) bahwa hubungan persepsi dengan bendanya tidaklah pasif melainkan kesadaran manusia secara aktif membentuk objek pengalaman.

Pemaknaan merupakan salah satu hal penting yang berlangsung sejalan dengan pengalaman. Tanpa adanya pemaknaan maka hidup akan menjadi hampa tanpa arti seperti yang diungkapkan oleh Heidegger "aku ada, maka aku berpikir” (Sobur, 2013: 257). Eksistensi membuat peneliti memahami pemaknaan secara aktif.

Ogden Dan Richards (dalam Sudaryat, 2009: 13) mendefinisikan makna (pikiran atau referensi) adalah hubungan antara lambang (simbol) dan acuan atau referen. Hubungan antara lambang dan acuan bersifat tidak langsung sedangkan hubungan antara lambang dengan referensi dan referensi dengan acuan bersifat langsung. Batasan makna ini sama dengan istilah pikiran, referensi yaitu hubungan antara lambang dengan acuan atau referen.

\section{Gambar 1 Segitiga Makna "Ogden dan Richard"}

\section{SEGITIGA MAKNA} "OGDEN \& RICHARD"

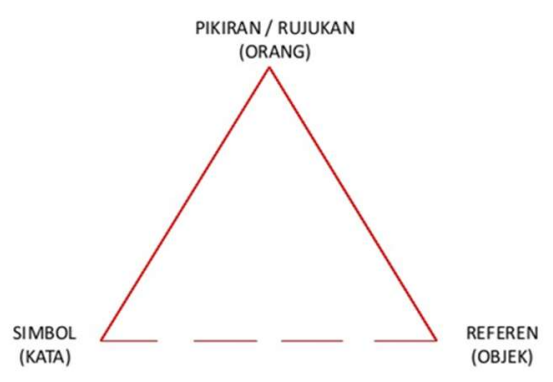


Terlebih, Frankl mengatakan bahwa diantara dimensi yang khas manusia ialah keinginan untuk mencari makna hidup (Sobur, 2013: 219). Dalam menemukan makna hidup, Viktor Frankl (dalam Sobur, 2013: 229-230) menawarkan tiga pendekatan. Makna dapat diperoleh dengan jalan merealisasikan tiga nilai kehidupan yang mencakup: creative values (nilai-nilai kreatif), experiental values (nilai-nilai penghayatan), dan attitudinal values (nilai-nilai bersikap) (Bastaman, 1996).

Antrozoologi ialah ilmu mengenai interaksi manusia dengan hewan. Kombinasi antara antropologi dengan zoologi mulai populer tahun 1987. Ilmu ini seharusnya mencakup ilmu konservasi, perdagangan hewan, dan ekologi hewan. Namun sekarang, antrozoologi lebih dirujuk pada relasi atau hubungan kedekatan manusia dengan hewan (human-animal bond), dibanding dengan untuk aspek penelaahan interaksi yang sebenarnya dapat diteliti secara antrozoologi (Mills, 2010: 28).

Kemudian, Bradshaw (2017: iii) melihat bahwa fenomena mengenai penganggapan bahwa peliharaan ialah anggota keluarga, dan memperlakukan mereka seperti "anak kecil” atau manusia lain sangatlah menarik untuk diteliti, sehingga peneliti memutuskan untuk meneliti objek terkait. Penelope Smith (dalam Liliweri 2011: 1004) juga mengatakan bahwa binatang juga dapat berkomunikasi dengan manusia secara bebas dan terbuka melalui "bahasa telepati". Binatang mempunyai perasaan, pikiran, dan tindakan, namun dia tidak memiliki bahasa verbal untuk mengungkapkan dirinya.

Liliweri (2011) menyatakan "animal communication", atau yang sering disebut sebagai "bahasa binatang" merupakan istilah "praktis" yang menjelaskan bentuk-bentuk perilaku kinestika, proksemik dan perilaku paralinguistik yang ditampilkan binatang ( $p$. 1006).

Pada hakekatnya manusia juga ialah hewan, Homo Erectus. Aristoteles (dalam Tasmara,
2000: 248) mengatakan bahwa manusia ialah hewan yang berpikir (man as the animal as reasons). Manusia sendiri sering berusaha menirukan sinyal komunikasi binatang saat berinteraksi dengan binatang lain. Gerakan membelai dan mengusap binatang peliharaan merupakan tindakan yang meskipun tamapk alami, perilaku yang sama juga terjadi di dalam spesies-spesies tersebut dalam komunikasi antarspesies. Seperti anjing, mereka dapat menggunakan komunikasi yang diajarkan manusia seperti gerak tubuh sebagai penunjuk arah, mengais makanan, dan mencari barang yang tersembunyi (Liliweri, 2011: 1026).

Richard Shulman (dalam Liliweri, 2011: 1029) mengatakan bahwa manusia dapat berkomunikasi dengan binatang, atau binatang dengan binatang spesies lain dengan menggunakan bahasa "telepati". Bahasa telepati ialah bahasa jiwa universal yang digunakan oleh semua spesies. Kemampuan ini merupakan perpanjangan intuisi alamiah.

Mulyana (2012: 260) mengemukakan bahwa simbol atau pesan verbal adalah semua jenis simbol yang menggunakan satu kata atau lebih. Suatu sistem kode verbal disebut sebagai bahasa. Bahasa dapat didefinisikan sebagai seperangkat simbol, dengan aturan untuk mengkombinasikan soimbol-simbol tersebut yang dipergunakan dan dipahami oleh suatu komunitas. Dalam komunikasi verbal manusia mengguakan bahasa verbal baik secara lisan, tertulis maupun elektronik (Hardjana, 2003: 23).

Fungsi bahasa yang mendasar ialah untuk menamai atau menjuluki orang, objek, dan peristiwa, berhubungan dengan orang lain dan untuk menyalurkan pesan seperti Menurut Larry L. Barker (dalam Mulyana 2012: 266) bahwa bahasa memiliki tiga fungsi yaitu, penamaan, interaksi dan transmisi informasi.

Kemampuan bahasa yang dikemas dalam kata-kata sangatlah terbatas, seterbatas jumlah kata karena tidak semua kata tersedia untuk merujuk pada suatu objek. Suatu kata dapat 
mewakili realitas, tetapi bukan realitas itu sendiri (Mulyana, 2012: 269).

Sedangkan Hardjana (2003: 26), menyatakan bahwa komunikasi nonverbal ialah komunikasi yang pesannya dikemas secara nonverbal, tanpa kata-kata. Komunikasi nonverbal jauh lebih banyak dipakai daripada komunikasi verbal karena dalam berkomunikasi, komunikasi nonverbal secara otomatis dapat ikut terpakai. Karena itu, komunikasi nonverbal bersifat tetap dan selalu ada.

Komunikasi nonverbal merupakan bentuk awal komunikasi yang mendahului evolusi bagian otak yang berkembang dalam penciptaan. Manusia sudah melakukannya sejak lahir hingga berumur delapan belas bulan, manusia secara total bergantung pada komunikasi nonverbal seperti sentuhan, senyuman, pandangan mata, dan sebagainya (Mulyana, 2012:342).

Menurut Liliweri (2011: 1029), telepati disebut sebagai aktivitas untuk mengungkapkan pikiran dengan pikiran. Para ahli sosiobiologi maupun etologi untuk sementara menyimpulkan bahwa manusia dapat berkomunikasi dengan binatang menggunakan bahasa "telepati". Bahasa telepati ialah bahasa jiwa universal yang digunakan oleh semua spesies. Kemampuan ini merupakan perpanjangan intuisi alamiah.

Menurut Ardianto (2010: 158) Interaksi simbolik (Symbolic Interactionism) juga memiliki asumsi bahwa setiap individu memiliki cara tertentu dalam melakukan pemaknaan, interpretatif (penafsiran), dan tindakan-tindakan. Mind (pikiran), self (diri), dan society (masyarakat) bekerja besama-sama mempengaruhi bagaimana individu melakukan pemaknaan.

Pertunjukan menurut Blacking (dalam Nakagawa 1999: 68) ialah ekspresi tubuh atau bisa dikatakan ekspresi dengan tubuh dalam menyanyi, bermain instrumen, menari, dan lainlain. Tubuh digunakan dengan sangat berbeda dengan penggunaan sehari-hari, tubuh digunakan sebagai alat yang istimewa. Suara, bunyi, instrumen, dan gerak menyebabkan perasaan atau emosi yang tidak terkendali dan hal itu muncul dengan sendirinya.

Seni pertunjukan mecakup teater, tarian, menyanyi, menari, musik instrumental, pantomim, vaudeville, aksi sirkus, pertunjukan kombinasi yang megah, dan wayang (Danesi, 2004: 190).

Mathis (2002: 5) memberikan definisi mengenai pelatihan adalah suatu proses dimana orang-orang mencapai kemampuan tertentu untuk membantu mencapai tujuan organisasi oleh karna itu, proses ini terikat dengan berbagai tujuan organisasi, pelatihan dapat dipandang secara sempit ataupun luas". Dapat diartikan secara luas oleh peneliti bahwa pelatihan ialah proses yang ada untuk belajar suatu kemampuan tertentu dengan tujuan tertentu.

Menurut Parker (dalam Schwagner \& Suerger, 2007: 40) tugas lain dari pelatih lumbalumba ialah memastikan lumba-lumba dalam fasilitas bahagia dan sehat. Pelatih lumba-lumba akan sangat bersahabat dengan lumba-lumba yang dilatih mereka, bahkan menganggap lumbalumba sebagai anak atau saudara pelatih.

Tugas utama dari pelatih lumba-lumba ialah melatih lumba-lumba. Dalam melatih, biasanya pelatih lumba-lumba menggunakan metode bernama penguatan positif (positive reinforcement) dan makanan. Nancy Parker (dalam Schwagner \& Suerger, 2007) menggambarkannya bahwa dengan kasih sayang, penghargaan, dan penguatan secara positif, segala perilaku baru dapat diajarkan kepada lumba-lumba. Kegembiraan lumba-lumba merupakan prioritas utama pelatih, pelatih harus membuat penampilan dan pembelajaran perilaku baru menyenangkan bagi mereka, agar tidak bosan (dalam Schwagner \& Schuerger, 2007: 42). Mulyana (2012: 48) juga mengatakan bahwa dalam melatih hewan bekerjasama dengan manusia untuk menghibur manusia seperti pertunjukan sirkus, berprinsip belajar operant conditioning 
Pengondisian Operan atau dikenal dengan operant conditioning merupakan teori pembelajaran yang dicetuskan oleh B.F. Skinner tahun 1930. Skinner (dalam Angela, 2017: 22) mendefinisikan belajar sebagai perubahan tingkah laku. Asumsi dasar skinner tidak terletak pada teori sebagai kerangka kerja, melainkan pada sifat pengondisian operan yang berpusat pada hakikat ilmu perilaku dan ciri-ciri tingkah laku hasil belajar.

Menurut Gunderson (2010: 4) lumba-lumba Hidung Botol ialah jenis lumba-lumba yang sering terlihat dan dipertontonkan dalam kebun binatang dan aquarium publik. Mulut yang cekung membuat mereka terlihat selalu tersenyum. Lumba-lumba hidung botol adalah salah satu hewan yang tercerdas di dunia.

Lumba - lumba hidung botol bernama ilmiah Tursiops Aduncus. Seperti lumba-lumba lainnya lumba-lumba hidung botol ialah cetacea, termasuk dalam famili Delphinidae. Lumbalumba hidung botol terbagi atas dua spesies yaitu lumba-lumba hidung botol biasa dan lumbalumba hidung botol Indo - Pasifik.

Lumba-lumba hidung botol dapat tumbuh dengan panjang sekitar $1,8 \mathrm{~m}$ sampai $4 \mathrm{~m}$, dan rata rata berberat badan 120-200 kg. Lumba-lumba ini memiliki ujung sirip dorsal yang melekuk ke belakang. Lumba-lumba hidung botol dapat ditemukan di seluruh belahan dunia kecuali yang bertemperatur dingin. Biasanya mereka ditemukan di laut dalam kelompok besar sekitar 15 ekor, walaupun kelompok seribu ekor juga pernah di temukan (Thewissen, Wursig, \& Kovacs, 2009: 252)

\section{Objek dan Metode Penelitian}

Penelitian ini menggunakan metode Kualitatif dengan pendekatan Fenomenologi Intepretatif, dengan mengolah data berupa transkrip dari rekaman wawancara. Moustakas dan Creswell (dalam Sobur 2013: 425) menyatakan bahwa fenomenologi merupakan strategi penelitian di mana di dalamnya peneliti mengidentifikasi hakikat pengalamanpengalaman hidup manusia tentang suatu fenomena tertentu. Memahami pengalaman hidup manusia mengharuskan peneliti untuk mengkaji sejumlah subjek dengan terlibat secara langsung dan relatif lama di dalamnya untuk mengembangkan pola serta relasi makna.

Begitu pula Alex Sobur (2013: 427) mengagas bahwa inti dari penelitian fenomenologi adalah ide atau gagasan mengenai "dunia kehidupan" (lifeworld), sebuah pemahaman bahwa realitas individu itu berbeda dan bahwa tindakan setiap individu hanya bisa dipahami melalui pemahaman terhadap dunia individu, sekaligus lewat sudut pandang mereka masing-masing.

Fenomenologi interpretatif menja-barkan pentingnya sebuah pengalaman sebagai signifikansi pemaknaan diri seorang individu, peneliti tidak mencari kebenaran mutlak namun mencari pemahaman dari observasi dan penelaahan secara detail untuk memahami pemaknaan dari pengalaman hidup informan dari pekerjaannya melatih, perform dan juga berinteraksi melakukan proses interaksi manusiahewan (antrozoologi) di "Dolphin Show" Ocean Dream Samudra. Melihat proses pemaknaan yang diberikan oleh pelatih saat melatih lumbalumba mengimplikasikan proses komunikasi.

Informan dalam penelitian ini ialah pelatihpelatih lumba-lumba yang melatih dan tampil untuk "Dolphin Show" Ocean Dream Samudra Ancol.

Fokus Penelitian ini adalah analisis mengenai pemaknaan pengalaman melatih lumba-lumba dan berusaha menangkap pola-pola pengalaman serupa pada subjek interaksi manusia-hewan (antrozoologi). Peneliti mencoba menggali lebih dalam mengenai alam pengalaman dari masingmasing pelatih. Masing-masing pelatih berasal dari berbagai macam latar belakang yang berbeda seperti budaya, pendidikan, tempat tinggal, 
lingkungan dan lain lain memungkinkan peneliti melihat perbedaan pemaknaan dalam melatih lumba-lumba.

Metode pengumpulan data yang digunakan dalam penelitian ini ialah wawancara semi terstruktur dan observasi partisipatif. Wawancara semi-terstruktur memungkinkan peneliti membangun suasana nyaman antara peneliti dengan informan. Model ini memungkinkan peneliti merancang serangkaian pertanyaan yang disusun dalam suatu daftar wawancara, tetapi daftar tersebut digunakan untuk menuntun, bukan untuk mendikte. Jenis pertanyaannya bersifat terbuka sehingga yang diwawancarai tidak merasa dibatasi (Smith, 2009). Peneliti juga menggunakan panduan wawancara untuk menjaga agar pertanyaan tetap sesuai dengan tujuan penelitian.

Selain wawancara, peneliti juga menggunakan observasi partisipatif yang memungkinkan peneliti terlibat dengan kegiatan yang dilakukan oleh sumber data penelitian. Sambil melakukan pengamatan, peneliti ikut merasakan suka duka apa yang dikerjakan oleh sumber data. Dengan observasi partisipan ini, data yang diperoleh akan lebih lengkap, tajam dan sampai mengetahui pada tingkat makna dari setiap perilaku yang nampak (Sugiyono, 2016: 64).

Teknik analisis data yang digunakan pada penelitian ini ialah analisis fenomenologi interpretatif. Peneliti akan melakukan prosedur analisis data dengan beberapa modifikasi dilakukan peneliti untuk mencapai kesimpulan. Analisis data dengan model Colaizzi (1978) (dalam Sobur, 2013: 456 -457) yang menganalisis data wawancara dan teks tertulis secara terpisah, namun tujuan akhirnya ialah untuk mendapatkan pemahaman menyangkut keseluruhan esensi fenomena yang diteliti. Colaizzi menjabarkan langkah-langkah seperti reading and re-reading, initial noting, merumuskan makna, klasifikasi, exhaustive description, essensi, member check.
Peneliti menggunakan triangulasi, yang diartikan sebagai teknik pengumpulan data yang bersifat menggabungkan dari berbagai teknik pengumpulan data dan sumber yang telah ada. Teknik triangulasi menggunakan teknik pengumpulan data yang berbeda dari sumber yang sama. Peneliti menggunakan observasi partisipatif, wawancara semi terstruktur dan dokumentasi untuk sumberdata yang sama secara serempak.

Penelitian di lakukan di Dolphinarium Ocean Dream Samudra- Ancol pada bulan Mei - Juni 2018.

Keterbatasan penelitian ini yang paling signifikan ialah prosedur birokrasi Taman Impian Jaya Ancol yang cukup berbelit sehingga proses penelitian menjadi lebih lambat. Kemudian, kemampuan intelektual pelatih dalam menjawab pertanyaan yang kurang dapat mengerti pertanyaan dalam skala filosofis.

\section{Hasil dan Pembahasan}

\subsection{Fakta Empirik Lapangan}

Taman Impian Jaya Ancol adalah salah satu pusat rekreasi utama dan terbesar di Indonesia, dicetuskan oleh presiden pertama Republik Indonesia Ir. Soekarno. Ocean Dream Samudra merupakan unit oceanarium terbesar di Indonesia yang terdiri atas pentas lumba-lumba, pentas singa laut, pentas aneka satwa, peragaan satwa, akuarium ikan laut dan tawar serta taman yang merupakan habitat beraneka macam burung. Terobosan Ancol ini menjadi pusat studi konservasi ex-situ lumba-lumba (dolphinarium) karena memiliki konsep dan manajemen lumbalumba yang paling lengkap.

Dolphin Show atau dikenal juga dengan pertunjukan lumba-lumba, menjadi salah satu atraksi yang paling dikunjungi di Ocean Dream Samudera karena teknologi layar LED dan icon lumba-lumba yang sudah melekat sebagai 
destinasi utama di Ocean Dream Samudera Ancol. Berdasarkam observasi peneliti, pertunjukan ini dikunjungi banyak pentonton karena setiap hari nya diadakan 2 kali show di hari biasa, dan 3 kali show di hari libur atau weekend. Seperti gambar dibawah, dolphin show ini terletak di dekat pintu masuk Ocean Dream Samudra sehingga menjadi penarik perhatian pertama saat memasuki Ocean Dream Samudra.

\section{Gambar 2.Peta Dolphin Show Ocean Dream Samudra}

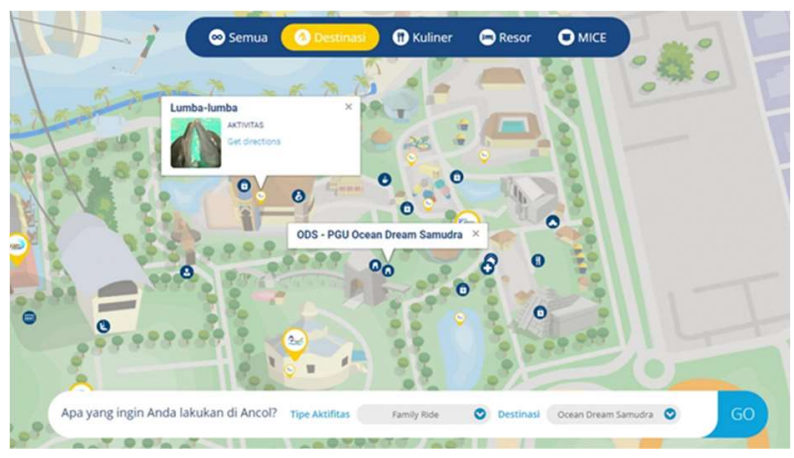

\subsection{Profil Informan Penelitian}

. Tabel 1. Profil Pelatih Lumba-Lumba

\begin{tabular}{|c|c|c|c|}
\hline & Informan 1 & $\begin{array}{c}\text { Informa } \\
\mathrm{n} \mathrm{2}\end{array}$ & $\begin{array}{c}\text { Informa } \\
\mathrm{n} \mathrm{3}\end{array}$ \\
\hline Nama & Dewi R & Agung T & Rivaldy \\
\hline $\begin{array}{c}\text { Nama } \\
\text { Panggun } \\
\text { g }\end{array}$ & Moana & Charlie & Aldi \\
\hline $\begin{array}{c}\text { Jenis } \\
\text { Kelamin }\end{array}$ & Wanita & Pria & Pria \\
\hline
\end{tabular}

\begin{tabular}{|c|c|c|c|}
\hline $\begin{array}{c}\text { Pekerjaa } \\
\mathrm{n}\end{array}$ & $\begin{array}{c}\text { Pelatih } \\
\text { lumba- } \\
\text { lumba dan } \\
\text { Ballerina } \\
\end{array}$ & $\begin{array}{c}\text { Pelatih } \\
\text { lumba- } \\
\text { lumba }\end{array}$ & $\begin{array}{c}\text { Pelatih } \\
\text { lumba- } \\
\text { lumba } \\
r\end{array}$ \\
\hline Umur & 24 & 28 & 20 \\
\hline
\end{tabular}

\subsection{Hasil Analisis Penelitian}

Paparan para ketiga informan dari wawancara yang dilakukan menunjukan bahwa pengalaman secara praktikal yang dialami pelatih bersama dengan lumba lumba meliputi banyak aspekaspek komunikasi seperti nonverbal, verbal, simbol-simbol maupun telepati. Para pelatih memiliki cara komunikasi tersendiri untuk berkomunikasi dengan hewan yang mungkin berbeda dengan komunikasi antar manusia.

Rasa sayang pada hewan, biasanya menjadi dasar seorang manusia mau berinteraksi positif secara kontinu dengan hewan. Menjadi pelatihpun biasanya bermotif akan rasa suka pada hewan, baik itu peliharaan maupun liar. Karena rasa sayang pada hewan memungkinkan para pelatih untuk memposisikan diri setara dengan lumba-lumba sehingga jenis komunikasi yang digunakan juga disesuaikan agar proses komunikasi lebih efisien, lebih lagi, proses mengalami nilai pengalaman yaitu interaksi dengan satwa dapat mengubah pribadi seseorang menjadi penyayang satwa tersebut.

Berbagai integrasi aspek komunikasi digunakan untuk menyampaikan instruksi bagi lumba-lumba untuk memahami trik. Pelatih menggunakan jenis komunikasi ini karena lebih mudah dimengerti oleh lumba-lumba, dan telah turun temurun diwariskan dari senior. Kemampuan lumba-lumba dalam mengikuti trik telah diajarkan dan dilatih dari lumba-lumba tersebut lahir, bahkan berganti-ganti pelatih selama belasan bahkan puluhan tahun. Sehingga 
tidak jarang pelatih-lah yang harus belajar trik tersebut.

Dalam berkomunikasi dengan hewan, komunikasi verbal juga dipakai namun, dengan jumlah terbatas, dikarenakan perbedaan jenis bahasa antara manusia dan hewan. Komunikasi verbal yang biasa dipakai ialah kata, ataupun frasa sederhana yang biasa diucapkan pada anakanak. Komunikasi verbal yang dipakai dalam melatih lumba-lumba ialah mayoritas lisan (katakata) dan sedikit tertulis (angka). Komunikasi secara lisan pasti dilakukan setiap hari, baik ungkapan, maupun instruksi.

Komunikasi nonverbal ialah jenis komunikasi yang paling sering dipergunakan oleh pelatih dalam berinteraksi dengan lumbalumba. Jenis komunikasi nonverbal yang digunakan dalam pertunjukan lumba-lumba dolphin show ini adalah gestur, objek, peluit ultrasonik, fokus tatapan mata, dan bahasa telepati.

Kombinasi jenis komunikasi ini memungkinkan terjadinya proses komunikasi dua arah antara pelatih dengan lumba-lumbanya. Proses komunikasi diawali dengan fokus tatapan mata kemudian melakukan koneksi batiniah sehingga terpancar interaksi dua arah, kemudian komunikasi verbal dan nonverbal menjadi stimulan untuk trik yang akan dilakukan. Tidak hanya trik, namun perasaan emosional dapat disampaikan dari pelatih kepada lumbalumbanya.

Pemaknaan pelatih dalam melatih juga berkaitan dengan simbol-simbol yang digunakan untuk memperoleh makna sehingga interpretasi suatu tanda dapat sejalan dengan perilaku lumbalumba. Pemaknaan pelatih akan suatu simbol dapat berubah karena dipengaruhi interaksi dengan lumba-lumba itu sendiri.

Interaksi simbolik dapat menjadi teori pendukung bagaimana makna dapat berubah sesuai dengan konteks waktu dan pengalaman yang dialami dalam interaksi baik pelatih maupun lumba-lumba yang dilatih.
Lebih lagi bukan hanya aspek pendukung interaksi manusia - lumba-lumba yang dapat berubah maknanya, namun makna dari diri pelatih dan lumba-lumba itu sendiri setelah melakukan suatu interaksi.

Konsistensi latihan selama bertahun-tahun, dari lumba-lumba tersebut kecil menjadikan pola trik sebagai suatu kebiasaan yang dilakukan untuk mendapatkan makanan, Namun makanan bukan hal utama dalam proses interaksi, makanan menjadi penyokong kuat pemancing keberhasilan proses komunikasi. Makanan menjadi reward saat lumba-lumba melakukan trik dengan benar, menjadi penggenap trik, penghargaan (reward) dari positive reinforcement trik dalam Operant Conditioning.

Kesalahan saat latihan, biasanya akan selalu di tolerir, dengan pengulangan. Namun saat show kegiatan pengulangan tersebut akan terkesan membosankan dan terlihat tidak profesional. Sehingga plotting dalam Dolphin Show ini menjadi sangat fleksibel karena bergantung bukan pada jalan cerita semata namun pada improvisasi pelatih.

Pelatih memaknai interaksi dengan lumbalumba sebagai nilai pengalaman dalam mengamalkan makna hidupnya sebagai pecinta hewan. Kecintaan pada lumba-lumba dapat pula ditumbuhkan dengan mengenal lebih dekat lumba-lumba tersebut.

Aspek komunikasi yang memiliki peranan terbesar yang dipergunakan hingga pelatih dapat melihat lumba-lumba mengerti instruksi ialah komunikasi non verbal (gestur) dan bahasa telepati, namun pengintegrasian aspek komunikasi seperti komunikasi verbal dan objek juga perlu sebagai sarana pendukung dalam menciptakan arus interaksi yang lebih efektif.

Komunikasi non verbal gestur mayoritas digunakan baik pelatih dan lumba-lumba, pelatih akan menggerakan tangan untuk memberikan isyarat instruksi trik kemudian lumba-lumba membalasnya dengan gerakan tubuh untuk menyampaikan sesuatu kepada pelatih. 
Sedangkan objek biasanya menjadi simbol yang diasosiasikan pada suatu trik khusus tertentu, seperti hulahoop diputar-putar di moncong, dan bola basket disundul. Suara ultrasonik dari peluit juga sering digunakan sebagai penanda tindakan yang harus dilakukan oleh lumba-lumba seperti berhenti, salah, dan memanggil.

Bahasa telepati yang di representasikan dengan fokus tatapan mata menjadi titik tolak pertama penjaga interaksi agar tetap berlangsung. Lumba-lumba juga dapat meghibur dan berempati pada pelatihnya jika kurang fokus. Komunikasi dua arah digambarkan pelatih, karena saling mengerti ialah kunci utama untuk menyuguhkan pertunjukan yang baik.

\section{Gambar 3. Lumba-lumba dalam posisi station}

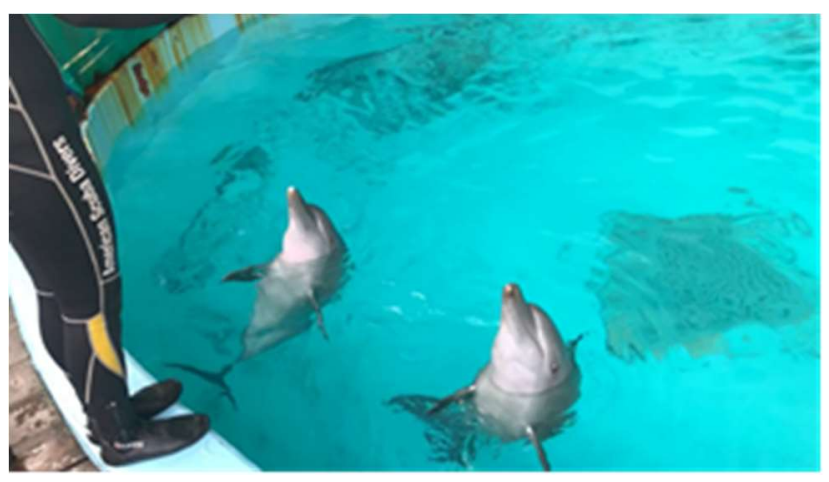

Pengalaman gagal dalam berkomunikasi dengan lumba-lumba biasanya tidak dianggap serius, akan dilatih berulang-ulang sampai baik atau di alihkan dengan menggunakan improvisasi saat show. Improvisasi yang dilakukan, dilakukan dengan kerjasama dengan Voice Over MC dan lumba-lumba itu sendiri.

Makanan menjadi penghargaan (reward) dari positive reinforcement trik yang telah berhasil.
Namun makanan bukanlah faktor utama yang memengaruhi keberhasilan. Konsistensi latihan bertahun-tahun dan kedispilinan yang diterapkan saat latihan juga menjadi faktor penting. Koneksi perasaan yang "cocok" dan konsistensi latihan akan membuat interaksi berhasil walaupun tanpa reward.

\section{Kesimpulan dan Rekomendasi}

Lumba-lumba, ialah salah satu hewan tercerdas di dunia dalam berkomunikasi, sehingga sering dipergunakan untuk sirkus dan terapi karena kemampuannya patuh pada manusia. Lumba-lumba dalam Ocean Dream Samudera - Ancol merupakan lumba-lumba konservasi yang telah dilatih oleh pelatih sehingga dapat menghibur dan membantu manusia.

Berdasarkan temuan peneliti, komunikasi non verbal dan bahasa telepati memiliki peranan terbesar dalam efektifitas pelatihan lumbalumba. Fokus melalui tatapan mata ialah titik tolak utama untuk memulai kegiatan interaksi.

Pelatih memaknai berinteraksi dengan lumba-lumba untuk berbuat baik bagi alam dan sesama, dengan melestarikan hewan dilindungi, mengedukasi masyarakat dan membantu penderita autis dan down syndrome.

Kemauan pelatih dalam berinteraksi didasari oleh rasa cinta pada hewan dari pelatih kepada hewan khususnya lumba-lumba. Lumba-lumba juga terkadang dapat menghantarkan afektif baik fisikal maupun emosional yang dirasakan oleh pelatih.

Pengalaman fenomenologis pelatih berkomunikasi dengan lumba-lumba menggunakan beberapa aspek komunikasi diantaranya komunikasi verbal, non verbal, objek, dan bahasa telepati. Komunikasi verbal berlaku sama seperti komunikasi antar manusia namun berperan kecil, sedangkan komunikasi 
nonverbal berperan sangat besar dalam bentuk gestur, objek dan tatapan mata.

Penggunaan simbol didalam benda dan gerakan fisik, memiliki makna yang terintegrasi dan progresif bagi pelatih dan lumba-lumbanya. Tidak hanya aspek pendukung interaksi manusia - lumba-lumba yang dapat berubah maknanya, namun makna dari diri pelatih dan lumba-lumba itu sendiri setelah melakukan suatu interaksi.

Pengalaman juga meliputi pelatihan yang didukung oleh kedisiplinan, konsistensi dan reward sehingga proses komunikasi dapat berjalan efektif saat pertunjukan. Reward menjadi apresiasi bagi kepatuhan lumba-lumba yang digunakan dalam proses pembelajaran berupa positive reinforcement

Kegagalan komunikasi juga kadang terjadi saat pertunjukan, namun karena kemampuan akting (improve) yang mahir, pertunjukan dapat berjalan dengan baik.

\section{Daftar Pustaka}

Ardianto, E. (2010). Metodologi Penelitian Untuk Public Relations Kuantitatif Dan Kualitatif. Bandung: Simbiosa Rekatama

Angela, N. F. (2017). Teori Belajar dan Pembelajaran Implementasinya dalam Pembelajaran Bahasa Indonesia di SMP, $S M A$, dan SMK. Yogyakarta: Budi utama

Bastaman, H. D. (1996). Meraih Hidup Bermakna. Jakarta: Paramadina

Bradshaw, J. (2017). The Animals Among Us: The New Science of Anthrozoology. London, Inggris: Penguin

Cresswell, J. (2010). The Oxford Dictionary of Word Origins (2 ed.). New York, Amerika Serikat: Oxford University Press.

Cohan \& Shires, L.M. (1988). Telling Stories: A theoritical analysis of narrative fiction. Routledge: London \& New York

Danesi, M. (2004). Pesan Tanda Dan Makna. Yogyakarta: Jalasutra

Growth From Knowledge. (2016). Global GFK survey: Pet Ownership [PDF File].
Diperoleh 5 September 2017 dari: http://www.gfk.com/global-studies/globalstudies-pet-ownership/

Gunderson, M. (2010). Bottlenose Dolphin. Ohio, Amerika Serikat: Checkerboard Books

Hardjana, A. M. (2003). Komunikasi Interpersonal Dan Intrapersonal. Yogyakarta: Kanisius

Kuswarno, E. (2009). Fenomenologi: Metodologi Penelitian Komunikasi. Bandung: Widya Padjajaran

Kittleson, K. (2013). How to Become a Dolphin Trainer. Diperoleh 6 September 2017 dari https://marinemammaltrainer.com/how-tobecome-a-dolphin-trainer/

Liliweri. A. (2011). Komunikasi Serba Ada Serba Makna. Jakarta: Kencana Prenada Media Group

Martin, D. (2016). Lumba Lumba Mamalia Tercerdas Setelah Manusia Ini Fakta Menariknya. Diperoleh 6 September 2017 dari

http://jateng.tribunnews.com/2016/10/14/umba-lumba-mamalia-tercerdas-setelahmanusia-ini-fakta-menariknya

Mathis R.L \& Jackson J.H. (2002). Manajemen Sumber Daya Manusia (D. Angelia, Trans.). Jakarta: Salemba Empat.

Merriam-Webster (2017). Animal. Diperoleh 6 September 2017 dari https://www.merriamwebster.com/dictionary/animal

Mills, D. S. (2010). Anthrozoology, The Encyclopedia of Applied Animal Behaviour and Welfare. Wallingford, Inggris: CABI

Mulyana, D. (2012). Ilmu Komunikasi: Sebuah Pengantar. Bandung: Rosda

Nakagawa. S. (1999). Musik Dan Kosmos: Sebuah Pengantar Etnomusikologi. Jakarta: Yayasan Obor Indonesia

Pembangunan Jaya Ancol. (n.d.). Lumba-lumba. Diperoleh 12 Januari 2018 dari https://www.ancol.com/id/aktivitas/lumbalumba id/destinasi/ocean-dream-samudra 
Ranneft, D. M., Eaker, H., \& Davis, R. W. (2001). A guide to the pronunciation and meaning of cetacean taxonomic names. Aquatic Mammals Journal, 27(02), 183-185. Diperoleh dari https://www.aquaticmammalsjournal.org/sh are/AquaticMammalsIssueArchives/2001/A quaticMammals 27-02/27-02 Ranneft.PDF

Robinson, I. (1995). The Waltham Book of Human-Animal Interaction. Oxford, Inggris: Pergamon.

Santoso, E., \& Setiansah, M. (2010). Teori Komunikasi. Yogyakarta: Graha Ilmu

Schwagner, T. \& Schuerger, M. (2007). Cool Woman Hot Jobs (C. Konggidinata, Trans.). Jakarta: Essensi Erlangga Griya

Sobur, A. (2013). Filsafat Komunikasi Tradisi dan Metode Fenomenologi. Bandung: Rosda

Sudaryat, Y. (2009). Makna dalam Wancana. Bandung: Yrama Widya

Tasmara. T. (2000). Menuju Muslim Kaffah: menggali potensi diri. Jakarta: Gema Insani

Thewissen, J. G. M., Wursig B., \& Kovacs, K. (2009). Encyclopedia of Marine Mammals. Massachusetts, Amerika Serikat: Academic Press

Undang-Undang Republik Indonesia. (1990). Konservasi Sumber Daya Alam Hayati Dan Ekosistemnya. Diperoleh 30 September 2017 dari http://www.dpr.go.id/dokjdih/document/uu/ 602.pdf

Vardiansyah, D. (2008). Filsafat Ilmu Komunikasi: Suatu Pengantar. Jakarta: PT Indeks.

Walgito, B. (2003). Psikologi Sosial. Yogyakarta: Andi Offset.

Washarti. (2016). Sirkus keliling lumba-lumba berbahaya tapi marak di Indonesia. Diperoleh $30 \quad$ Oktober 2017 dari http://www.bbc.com/indonesia/majalah/2016/01/160126 indonesia sirkus lumbal umba
White, T. L. (2007) In Defense of Dolphins: The New Moral Frontier. New Jersey, Amerika Serikat: Wiley-Blackwell

Wiji. U. (2012). Inilah Rahasia Kecerdasan Lumba-lumba. Diperoleh 27 Juni 2018 dari http://sains.kompas.com/read/2012/06/27/1 0385953/Inilah.RahasiaKecerdasan.Lumbalumba 